\title{
Consumption Externalities, Habit Formation and Equilibrium Efficiency*
}

\author{
Jaime Alonso-Carrera \\ Universidade de Vigo, ES-36310 Vigo, Spain \\ jalonso@uvigo.es
}

\section{Jordi Caballé}

Universitat Autònoma de Barcelona, ES-08193 Bellaterra (Barcelona), Spain

jordi.caballe@uab.es

\section{Xavier Raurich}

Universitat de Girona, ES-17071 Girona, Spain

xavier.raurich@udg.es

\begin{abstract}
We analyze the welfare properties of the competitive equilibrium in a capital accumulation model where individual preferences are subject to both habit formation and consumption spillovers. Using an additive specification for preferences, according to which the argument in the utility function is a linear combination of present and past values of own consumption and consumption spillovers, we analyze the circumstances under which these spillovers are a source of inefficiency. It is shown that consumption externalities have to interact with habits in order to generate an inefficient dynamic equilibrium. Finally, we characterize optimal tax policies aimed at restoring efficient decentralized paths.
\end{abstract}

Keywords: Habit formation; consumption externalities; equilibrium efficiency JEL classification: D91; E62; O40

\section{Introduction}

In this paper we analyze the welfare properties of the competitive equilibrium in a capital accumulation model where individual preferences are subject to both a process of habit formation and spillovers from the other

\footnotetext{
* We thank the anonymous referees of this Journal and the participants in a seminar at the Universidad Carlos III of Madrid and in the Encuentro de Economía Pública in Tenerife for their valuable comments. Of course, they should not bear any responsibility for remaining errors. Financial support from the Spanish Ministry of Science and Technology through grants SEC20000684, BEC2002-01995, SEC2003-00306 and HI2001-0039, and from the Generalitat of Catalonia through the Barcelona Economics program of CREA and grant SGR2001-00162 is gratefully acknowledged.

(C) The editors of the Scandinavian Journal of Economics 2004. Published by Blackwell Publishing, 9600 Garsington Road, Oxford, OX4 2DQ, UK and 350 Main Street, Malden, MA 02148, USA.
} 
agents' consumption. Intertemporal general equilibrium models have traditionally assumed that individual tastes are exogenous in the sense that, in each period, agents derive utility exclusively from the absolute level of their own current consumption. We consider instead a model where tastes are endogenous, since the utility derived from a given level of present consumption depends on a reference level, which can be viewed as a (time-varying) standard of living. More precisely, we assume that the argument in the agents' utility function is an additive combination of present and past values of individual consumption and consumption spillovers. It should be pointed out that a growing number of papers in macroeconomics have introduced endogenous preferences in order to account for some economic facts that cannot be reconciled with the more traditional theories based on exogenous preferences. ${ }^{1}$ Even if these papers view consumption externalities as a relevant phenomenon, a comprehensive analysis of the circumstances under which these externalities give rise to inefficiency is missing in the literature. In this paper we perform such an analysis and show that the existence of inefficiency requires consumption externalities to interact with some form of habits.

The introduction of habit formation implies that the individuals of our model derive utility from the comparison of the current level of own consumption with that of the previous period. Therefore, when individuals choose their current consumption, they are simultaneously setting a standard of living that will be used to evaluate the utility accruing from the level of future consumption. We assume that past consumption imposes a minimum level for future consumption and, hence, we use an additive functional form to introduce habits. This is in contrast to the "multiplicative" specification considered by other authors such as Abel (1990), Carroll et al. (1997, 2000) and Carroll (2000). The reason for our choice is that the additive formulation allows us to maintain the usual concavity property of the utility function. Moreover, some empirical studies have also used the additive specification of habits to reconcile theory with consumption data; see, for instance, Ferson and Constantinides (1991) and Heaton (1995).

We also assume that the benchmark level of consumption of an individual is affected by the level of consumption of his neighbors. ${ }^{2}$ More precisely,

\footnotetext{
${ }^{1}$ Examples of this literature include Abel $(1990,1999)$ and Galí(1994), who look at the implications for the equity premium puzzle; Lettau and Uhlig (2000), who analyze some stylized business cycle facts; Ljungqvist and Uhlig (2000), who examine the effects of fiscal policy; and Carroll Overland and Weil $(1997,2000)$ and Shieh, Lai and Chang (2000), who study how the patterns of growth are modified when preferences are time-dependent.

${ }^{2}$ Based on a survey study, Solnick and Hemenway (1998) conclude that relative consumption positions may affect individual satisfaction.
} 
our individuals' utility will depend on both the lagged and the current levels of average consumption in the economy. These consumption spillovers may either reduce or increase the felicity that each individual obtains from his own (habit-adjusted) consumption. Thus, the individuals of our model could exhibit either jealousy or altruism. Moreover, these consumption spillovers could either reduce or increase the private marginal utility of consumption. Therefore, our model encompasses both the "catching up with the Joneses" and the "keeping up with the Joneses" features introduced by Abel (1990) and Galí (1994), respectively. In the former case the lagged value of others' consumption makes the marginal increase of current own consumption more valuable, while in the latter case the current value of others' consumption increases the private marginal utility. In order to be consistent with the functional form used to introduce habits, we also apply the additive specification for consumption spillovers. Therefore, the argument appearing in the individuals' utility function turns out to be an additive combination of the current level of own consumption, the lagged value of own consumption, the current level of average consumption and the lagged value of average consumption.

The rest of the model has the typical features of a deterministic economy with infinitely lived agents. The production side is modeled by means of a standard neoclassical production function exhibiting constant returns to scale. The equilibrium exhibits transitional dynamics driven by both the decreasing returns to capital and the time dependence of preferences. Note that consumption does not adjust instantaneously to its benchmark level, since the standard of living derived from past consumption is fixed in each period.

Consumption externalities constitute a potential source of equilibrium inefficiency as individuals do not take them into account when they choose their individual consumption paths. We will show that the competitive equilibrium is always efficient at the steady state, whereas it is dynamically inefficient under some conditions. In particular, our analysis will show that, under the additive specification of preferences, the key element for the existence of dynamic inefficiency is the interaction of consumption externalities with time dependent preferences. Thus, on the one hand, the externality associated with current average consumption does not generate inefficiency as long as individuals' preferences are not subject to either a process of habit formation or spillover effects from others' past consumption. Under timeindependent preferences, contemporaneous externalities do not have intertemporal effects on the marginal utility of own consumption and, thus, the functional form of the marginal rate of substitution of a competitive economy is identical to that of the social planner. In the presence of habits, contemporaneous consumption externalities affect the future standard of living and, thus, they have consequences for the individuals' willingness to substitute 
consumption across periods. Since a benevolent social planner would internalize these consumption spillovers, the marginal rate of substitution between consumption, at different periods, of an individual who behaves competitively differs from that of the social planner. ${ }^{3}$ On the other hand, the externality associated with past average consumption generates inefficiency even in the absence of habit formation. These consumption spillovers already generate the required time dependency of preferences by themselves as they affect the future standard of living.

The existence of inefficient competitive paths calls for a tax policy aimed at replicating the socially planned solution. We characterize the optimal rates of both a capital income tax and a consumption tax. We show that, if individuals' willingness to shift present consumption to the future is suboptimally low along the socially planned solution, equilibrium efficiency will be achieved by means of either subsidizing capital income or introducing a tax on consumption with a tax rate falling over time. These tax policies decrease the relative price of future consumption and encourage individuals to shift consumption from the present to the future. Moreover, the optimal rates of the capital income tax and of the consumption tax converge to zero and to a constant value, respectively, since no inefficiencies appear at a steady state.

The outline of the paper is as follows. Section II introduces the benchmark model where preferences are determined endogenously. In Section III we derive the equilibrium path of the competitive economy, while in Section IV we characterize the solution of the socially planned economy. Section V addresses the efficiency properties of the competitive equilibrium. We characterize the optimal taxation policy in Section VI. Section VII concludes.

\section{The Model}

The economy is composed of a continuum of identical individuals who face an infinite lifetime in discrete time. The population grows at a constant exogenous growth rate $n>-1$. We assume that individuals derive utility from the comparison between current own consumption and a reference level. This reference level is determined by the lagged value of individuals' own consumption and by the current and the lagged average values of consumption in the economy. We thus posit the following instantaneous utility function:

\footnotetext{
${ }^{3}$ Ljungqvist and Uhlig (2000) use a similiar linear specification of the utility function and show that, even with time-independent preferences, the contemporaneous consumption externality also generate, inefficiency when labor supply is endogenous. In this case, although the externality does not distort the intertemporal choice of consumption, it still distorts the intratemporal choice between consumption and leisure.
} 


$$
u\left(c_{t}, c_{t-1}, \bar{c}_{t}, \bar{c}_{t-1}\right)=\frac{\left(c_{t}-\gamma c_{t-1}-\alpha \bar{c}_{t-1}-\theta \bar{c}_{t}\right)^{1-\sigma}}{1-\sigma},
$$

where $c_{t}$ is the consumption of the individual under consideration in period $t$ and $\bar{c}_{t}$ is the average consumption of the economy in period $t$. We assume that the preference parameters satisfy $\sigma>0, \gamma \in(0,1)$ and $\theta<1$. The parameter $\sigma$ becomes the inverse of the elasticity of intertemporal substitution when $\gamma=\alpha=\theta=0$. The particular case with $\gamma>0$ and $\alpha=\theta=0$ corresponds to the typical habit formation model where the amount of own consumption in the previous period becomes a standard of living that is used to evaluate the utility of current consumption. The parameter $\gamma$ thus measures the importance of the reference set by past own consumption. We assume that $\gamma>0$ for consistentency with the notion of habits. Thus, current utility is decreasing in past consumption for a given amount of present consumption. Moreover, the condition $\gamma<1$ is imposed to guarantee that the discounted sum of utilities increases with the consumption level in any arbitrarily given period. As in Constantinides (1990) and Campbell and Cochrane (1999), among others, we use an additive specification for modeling habit formation instead of the multiplicative one suggested by other such as Abel $(1990,1999)$ and Carroll et al. $(1997,2000)$. The latter formulation would force us to consider only the case where the parameter $\sigma$ takes a value larger than one in order to obtain interior solutions for the competitive consumption path. ${ }^{4}$ Our specification of habit formation avoids this problem at the cost of potentially having negative habit-adjusted consumption and, hence, the utility function would not be well-defined in this case; see Carroll (2000). In our deterministic framework, this problem is easily solved by imposing the appropriate parametric conditions that ensure a positive value for habits adjusted consumption.

Individual preferences also exhibit consumption externalities that affect both the individual's utility level and the marginal utility of individual consumption. On the one hand, if $\theta \neq 0$, then individuals' utility is affected by an externality arising from the current average consumption in the economy. When $\theta>0$, individuals turn out to be jealous, since aggregate consumption reduces the individual's utility for a given level of own consumption. Moreover, since others' consumption in this case increases the marginal utility of own consumption, individual preferences exhibit the "keeping up with the Joneses" feature discussed in Galí (1994). If $\theta<0$, then individuals turn out to be altruistic, since utility is increasing in aggregate consumption. Here, others' consumption makes an additional unit of own consumption less valuable. The restriction $\theta<1$ will be needed

${ }^{4}$ Alonso-Carrera, Caballé and Raurich (2003) deal with this issue. 
in order to obtain an objective function that is increasing in current consumption and concave for the social planner's problem. On the other hand, if $\alpha \neq 0$, then individuals care about the lagged value of average consumption in the economy. In particular, when we assume $\alpha>0$ in (1), an individual feels jealous if others' past consumption increases and preferences then exhibit the "catching up with the Joneses" feature introduced by Abel (1990). ${ }^{5}$ The case $\alpha<0$ obviously means that a rise in others' past consumption results in an increase in current felicity.

Note that, in order to be consistent with the specification used for the process of habit formation, we posit the additive formulation to introduce consumption spillovers. As pointed out above, we have to impose conditions that ensure a positive value of the argument of the utility function (1) along the equilibrium path of consumption. By simply imposing that $\gamma+\alpha+\theta<1$, we can guarantee that the utility function will be well-defined around a stationary consumption path. From now on, we assume that the previous inequality holds.

Each individual inelastically supplies one unit of labor in each period. A single good is produced in each period by means of a constant-returns-toscale technology, which uses labor and capital as inputs. Gross output per capita $y_{t}$ is thus a function of capital per capita $k_{t}$,

$$
y_{t}=f\left(k_{t}\right),
$$

where the per capita production function $f$ satisfies the standard neoclassical properties, $f^{\prime}\left(k_{t}\right)>0$ and $f^{\prime \prime}\left(k_{t}\right)<0$, for $k_{t}>0$, and the usual Inada conditions. The single good of the economy can be either consumed or invested.

The government in this economy sets flat rate taxes on capital income and on consumption. We allow both tax rates to be time-varying. The fiscal revenues are returned to individuals by means of a lump-sum subsidy. Hence, the budget constraint of the government is as follows:

$$
\tau_{t}^{k} r_{t} k_{t}+\tau_{t}^{c} c_{t}=S_{t}
$$

where $\tau_{t}^{k}$ and $\tau_{t}^{c}$ are, respectively, the capital income tax rate and the consumption tax rate at time $t, r_{t}$ is the rental rate of capital, and $S_{t}$ is a lump-sum transfer per capita. The budget constraint faced by an individual is thus

$$
\left(1+\tau_{t}^{c}\right) c_{t}=w_{t}+\left[1+\left(1-\tau_{t}^{k}\right) r_{t}-\delta\right] k_{t}+S_{t}-(1+n) k_{t+1},
$$

\footnotetext{
${ }^{5}$ When preferences display the "catching up with the Joneses" feature, it is also said that they are subject to a process of "external habit formation".
} 
where $w_{t}$ is the rental rate of labor and $\delta \in[0,1]$ is the depreciation rate of the capital stock.

In the next two sections we analyze the competitive equilibrium and the socially planned solution of this economy.

\section{The Competitive Equilibrium}

In the competitive economy, factor prices are equated to marginal productivities so that

$$
w_{t}=f\left(k_{t}\right)-f^{\prime}\left(k_{t}\right) k_{t},
$$

and

$$
r_{t}=f^{\prime}\left(k_{t}\right) .
$$

Each individual chooses a sequence of consumption $\left\{c_{t}\right\}_{t=0}^{\infty}$ in order to maximize

$$
\sum_{t=0}^{\infty} \beta^{t} u\left(c_{t}, c_{t-1}, \bar{c}_{t}, \bar{c}_{t-1}\right)
$$

subject to the budget constraint (3), for a given sequence $\left\{\bar{c}_{t}\right\}_{t=-1}^{\infty}$ of average consumption and for the given initial conditions on capital $k_{0}$ and on consumption $c_{-1}$. The parameter $\beta \in(0,1)$ is the subjective discount factor. In order to simplify the exposition, let us define $u(t) \equiv u\left(c_{t}, c_{t-1}, \bar{c}_{t}, \bar{c}_{t-1}\right)$, $u_{1}(t) \equiv \partial u\left(c_{t}, c_{t-1}, \bar{c}_{t}, \bar{c}_{t-1}\right) / \partial c_{t} \quad$ and $\quad u_{2}(t) \equiv \partial u\left(c_{t}, c_{t-1}, \bar{c}_{t}, \bar{c}_{t-1}\right) / \partial c_{t-1}$. Moreover, according to (1), and using the fact that in a symmetric equilibrium $c_{t}=\bar{c}_{t}$ for all $t$, we observe that in equilibrium,

$$
u_{1}(t)=\frac{(1-\sigma) u(t)}{(1-\theta) c_{t}-(\gamma+\alpha) c_{t-1}},
$$

and

$$
u_{2}(t)=-\gamma u_{1}(t) .
$$

The first-order conditions of the previous problem are thus

$$
\beta^{t} u_{1}(t)+\beta^{t+1} u_{2}(t+1)=\lambda_{t}\left(1+\tau_{t}^{c}\right)
$$

and 


$$
(1+n) \lambda_{t}=\lambda_{t+1}\left(1+\left(1-\tau_{t+1}^{k}\right) r_{t+1}-\delta\right),
$$

for all $t$, where $\lambda_{t}$ denotes the shadow price of capital in period $t$.

The competitive equilibrium is defined by the positive paths of $c_{t}, k_{t}$ and $\lambda_{t}$ satisfying conditions (8) and (9), the budget constraint (3), the budget constraint of the government (2), the profit-maximizing conditions (4) and (5), the transversality conditions

$$
\begin{gathered}
\lim _{t \rightarrow \infty} \lambda_{t} k_{t+1}=0, \\
\lim _{t \rightarrow \infty} \beta^{t} u_{1}(t) c_{t}=0,
\end{gathered}
$$

and the initial conditions on $k_{0}$ and $c_{-1}$. Note that past consumption is a state variable when preferences are subjected to habit formation. In this case, the solution to the optimization problem requires an additional transversality condition besides the typical condition involving the capital stock.

Combining equations (8) and (9), and plugging (5) into the resulting equation, we obtain

$$
\underbrace{\frac{u_{1}(t+1)+\beta u_{2}(t+2)}{u_{1}(t)+\beta u_{2}(t+1)}}_{M R S^{d}\left(c_{t+2}, c_{t+1}, c_{t}, c_{t-1}\right)}=\left[\frac{1+\tau_{t+1}^{c}}{1+\tau_{t}^{c}}\right]\left[\frac{1+n}{\beta\left[1+\left(1-\tau_{t+1}^{k}\right) f^{\prime}\left(k_{t+1}\right)-\delta\right]}\right],
$$

which is the Euler condition equating the marginal rate of substitution (henceforth MRS) of consumption between periods $t$ and $t+1$ with the corresponding marginal rate of transformation (henceforth MRT). Note equation (12) differs from the Euler equation appearing in standard models of capital accumulation because, here, consumers take into account the effect of current consumption when setting the reference for next-period consumption.

Let us define the gross rate of growth of consumption,

$$
x_{t}=\frac{c_{t}}{c_{t-1}},
$$

and the gross rate of growth of the marginal utility $u_{1}(t)$,

$$
\phi_{t}=\frac{u_{1}(t+1)}{u_{1}(t)} .
$$


Substituting (7) and (14) into (12), we obtain

$$
\left[\frac{1-\beta \gamma \phi_{t+1}}{1-\beta \gamma \phi_{t}}\right] \phi_{t}=\left[\frac{1+\tau_{t+1}^{c}}{1+\tau_{t}^{c}}\right]\left[\frac{1+n}{\beta\left[1+\left(1-\tau_{t+1}^{k}\right) f^{\prime}\left(k_{t+1}\right)-\delta\right]}\right] .
$$

Next, we combine the functional form (1) with the definition of the variable $\phi_{t}$ given in (14), and then substitute the resulting expression in (13). Thus, we get

$$
x_{t+1}=\left(\frac{\gamma+\alpha}{1-\theta}\right)+\phi_{t}^{-\frac{1}{\sigma}}\left[1-\left(\frac{1}{x_{t}}\right)\left(\frac{\gamma+\alpha}{1-\theta}\right)\right] .
$$

Combining the government and the individual budget constraints (2) and (3), and substituting (4) and (5) in the resulting equation, we obtain the resource constraint

$$
k_{t+1}=\frac{f\left(k_{t}\right)+(1-\delta) k_{t}-c_{t}}{1+n} .
$$

The system of first-order difference equations (13), (15), (16) and (17), together with the transversality conditions (10) and (11), and the initial conditions on $k_{0}$ and $c_{-1}$, fully characterize the equilibrium path of the variables $x_{t}, \phi_{t}, c_{t}$ and $k_{t}$.

Let us now assume that the government follows a stationary tax policy, that is, $\tau_{t}^{c}=\tau^{c}$ and $\tau_{t}^{k}=\tau^{k}$ for all $t$. At a steady state of the system of dynamic equations (13), (15), (16) and (17), the variables $x_{t}, \phi_{t}, c_{t}$ and $k_{t}$ are all constant. We suppress the time sub-indices to denote the stationary values of the variables under consideration. The following proposition characterizes the stationary equilibrium of the model:

Proposition 1. Let $\beta\left(1-\tau^{k}\right) \in(0,1)$ and $\tau^{c}>-1$. An interior stationary equilibrium exists if and only if the following condition holds:

$$
1+n>\beta(1-\delta)
$$

Moreover, this equilibrium satisfies

$$
\begin{gathered}
x=\phi=1, \\
f^{\prime}(k)=\frac{1+n-\beta(1-\delta)}{\beta\left(1-\tau^{k}\right)},
\end{gathered}
$$


and

$$
c=f(k)-(n+\delta) k
$$

Proof: See the Appendix.

The parametric restrictions that appear in the preceding proposition are assumed to hold throughout the rest of the paper. To provide an analytical characterization of the stability properties of the steady state of the previous four-dimensional dynamic system turns out to be an infeasible task. However, we have analyzed these properties by performing systematic numerical simulations of the dynamic system formed by equations (13), (15), (16), and (17). In particular, we consider a benchmark example with a Cobb-Douglas production function of the form $y_{t}=A k_{t}^{\omega}$, and the following parameter configuration: $\mathrm{A}=1, \omega=0.36, \quad n=0.012, \quad \beta=0.969$, $\delta=0.064, \sigma=2, \gamma=0.15, \alpha=0.35, \theta=0.35, \tau^{k}=0$ and $\tau^{c}=0$. The values of $A, \omega, n, \beta, \delta$ and $\sigma$ were chosen according to a standard calibration procedure; see Cooley and Prescott (1995). Since there is no conclusive evidence on the values of the preference parameters $\gamma, \alpha$ and $\theta$, we use a grid of values within the largest range found in the literature. On the one hand, the empirical literature on habits reports values of $\gamma$ that go from zero to 0.7 depending on the goods and services under consideration; see Dynan, (2000); and Carrasco, Labeaga and López, (2002). On the other hand, we fix $\alpha=\theta$ and then use values of these two parameters so that the steady-state surplus of present consumption relative to the consumption reference, $1-\gamma$ $-\alpha-\theta$, lies on the interval [0.05,1]; see Campbell and Cochrane (1999). In all our simulations we have found that the steady state exhibits saddle-path stability, i.e., two of the eigenvalues of the dynamic system have moduli smaller than one. We conjecture that this stability result holds for the whole set of feasible parameter values. From now on, we then assume that the steady state of our model is saddle-path stable so that, for given initial conditions on $k_{0}$ and $c_{-1}$, the equilibrium path converges to the steady state characterized above.

Next, we can characterize the long-run effects of changes in the stationary tax rates $\tau^{c}$ and $\tau^{k}$. These effects immediately follow from performing a comparative static analysis over the expressions of $c$ and $k$ in (20) and (21). We observe that $k$ is decreasing in $\tau^{k}$. Moreover, a change in the stationary tax rate $\tau^{c}$ has no long-run effects. These results coincide with those obtained in the standard neoclassical growth model; see Hall (1971) and Brock and Turnovsky (1981) among many others. In fact, the steady state derived in this model with endogenous tastes coincides with the steady state of the standard neoclassical model. This occurs because the steady state is independent of the preference parameters $\gamma, \alpha$ and $\theta$. 


\section{The Efficient Solution}

We now turn our attention to the solution that a social planner would implement. This solution is also called the efficient solution. The planner internalizes the consumption spillovers and, thus, perceives the following instantaneous utility function:

$$
\hat{u}\left(c_{t}, c_{t-1}\right) \equiv u\left(c_{t}, c_{t-1}, c_{t}, c_{t-1}\right)=\frac{\left[(1-\theta) c_{t}-(\gamma+\alpha) c_{t-1}\right]^{1-\sigma}}{1-\sigma} .
$$

Moreover, the aggregate resource constraint per capita faced by the social planner is exactly equation (17). Define $\hat{u}(t) \equiv \hat{u}\left(c_{t}, c_{t-1}\right), \hat{u}_{1}(t) \equiv \partial \hat{u}\left(c_{t}, c_{t-1}\right) / \partial c_{t}$ and $\hat{u}_{2}(t) \equiv \partial \hat{u}\left(c_{t}, c_{t-1}\right) / \partial c_{t-1}$. According to (22), we observe that

$$
\hat{u}_{1}(t)=\hat{u}(t)\left[\frac{(1-\sigma)(1-\theta)}{(1-\theta) c_{t}-(\gamma+\alpha) c_{t-1}}\right]
$$

and

$$
\hat{u}_{2}(t)=-\hat{u}_{1}(t)\left[\frac{\gamma+\alpha}{1-\theta}\right] .
$$

Our parametric restrictions $\theta<1$ and $\gamma+\alpha+\theta<1$ ensure that the function $\hat{u}$ will be well-defined, increasing in current consumption, and concave (see (23)). Let $\hat{\lambda}_{t}, \hat{c_{t}}$ and $\hat{k}_{t}$ denote the efficient shadow price of capital, the efficient amount of consumption and the efficient amount of capital, respectively. Then, the socially planned equilibrium is defined by the positive paths of $\hat{c_{t}}, \hat{k}_{t}$ and $\hat{\lambda}_{t}$, satisfying the condition

$$
\underbrace{\frac{\hat{u}_{1}(t+1)+\beta \hat{u}_{2}(t+2)}{\hat{u}_{1}(t)+\beta \hat{u}_{2}(t+1)}}_{M R S^{p}\left(\hat{c}_{t+2}, \hat{c}_{t+1}, \hat{c}_{t}, \hat{c}_{t-1}\right)}=\frac{1+n}{\beta\left[1+f^{\prime}\left(\hat{k}_{t+1}\right)-\delta\right]},
$$

in addition to the resource constraint (17) expressed in terms of the efficient values of capital and consumption, the transversality conditions

$$
\begin{gathered}
\lim _{t \rightarrow \infty} \hat{\lambda}_{t} \hat{k}_{t+1}=0, \\
\lim _{t \rightarrow \infty} \beta^{t} \hat{u}_{1}(t) \hat{c}_{t}=0,
\end{gathered}
$$

and the initial conditions on $\hat{k}_{0}$ and $\hat{c_{-1}}$. 
Let us define the gross rate of growth of the planner's marginal utility $\hat{u_{1}}(t)$,

$$
\hat{\phi}_{t}=\frac{\hat{u}_{1}(t+1)}{\hat{u}_{1}(t)} .
$$

Then, we can replicate the analysis performed when solving for the competitive solution in order to obtain the following system of first-order difference equations, which fully characterize the socially planned solution:

$$
\begin{gathered}
\hat{x}_{t}=\frac{\hat{c}_{t}}{\hat{c}_{t-1}}, \\
{\left[\frac{1-\theta-\beta(\gamma+\alpha) \hat{\phi}_{t+1}}{1-\theta-\beta(\gamma+\alpha) \hat{\phi}_{t}}\right] \hat{\phi}_{t}=\frac{1+n}{\beta\left[1+f^{\prime}\left(\hat{k}_{t+1}\right)-\delta\right]},} \\
\hat{x}_{t+1}=\left(\frac{\gamma+\alpha}{1-\theta}\right)+\hat{\phi}_{t}^{-\frac{1}{\sigma}}\left[1-\left(\frac{1}{\hat{x}_{t}}\right)\left(\frac{\gamma+\alpha}{1-\theta}\right)\right]
\end{gathered}
$$

and

$$
\hat{k}_{t+1}=\frac{f\left(\hat{k}_{t}\right)+(1-\delta) \hat{k}_{t}-\hat{c}_{t}}{1+n},
$$

together with the transversality conditions (26) and (27) and the initial conditions on $\hat{k}_{0}$ and $\hat{c_{-1}}$. We can easily check that the difference equations (28), (30) and (31), which characterize the socially planned solution, are the exact counterparts of equations (13), (16) and (17), which characterize the competitive equilibrium. Therefore, the competitive and the socially planned solutions differ only in the equations that drive the evolution of $\phi_{t}$ and $\hat{\phi}_{t}$ (see (15) and (29)).

Proposition 2. An interior stationary equilibrium in the socially planned economy exists if and only if condition (18) holds. Moreover, along this equilibrium, the values of $\hat{\phi}, \hat{x}, \hat{c}$ and $\hat{k}$ coincide with the stationary values of their counterparts in the competitive economy with $\tau_{t}^{k}=0$ and $\tau_{t}^{c}=\tau_{t+1}^{c}$ for all $t$.

Proof: Obvious from evaluating equations (28)-(31) at $\hat{\phi}_{t}=\hat{\phi}, \hat{x}_{t}=\hat{x}, \hat{c_{t}}=\hat{c}$ and $\hat{k}_{t}=\hat{k}$ for all $t$. By looking at equations (19)-(21), we can check that $\hat{\phi}=\phi, \hat{x}=x \quad \hat{c}=c$ and $\hat{k}=k$ whenever $\tau_{t}^{k}=0$ and $\tau_{t}^{c}=\tau_{t+1}^{c}$ for all $t$. 
Finally, using the arguments in the proof of Proposition 1, we can prove immediately that $\hat{\lambda}_{t}>0$ and that the transversality conditions (26) and (27) hold at the steady state.

The preceding proposition tells us that, when the tax rate on capital income is zero and the tax rate on consumption is constant, the steady state of the competitive solution coincides with that of the efficient solution. Following a numerical analysis equivalent to that performed for the competitive equilibrium, it can be shown that the steady state of the socially planned solution is saddle-path stable under the same parameter configurations.

\section{Equilibrium Efficiency}

The competitive equilibrium could be inefficient in our model because individuals do not take into account the spillover effects arising from consumption. In fact, there are two potential sources of inefficiency: the externality associated with the lagged value of average consumption and that generated by the current level of average consumption. These externalities make individuals choose the current level of consumption without completely internalizing the effects on present and future marginal utilities. We now study the conditions under which a non-efficient path emerges in equilibrium.

Comparing the equations characterizing the competitive equilibrium with those characterizing the social planner's solution, we observe that the only difference is in the Euler equations (see (12) and (25)). More precisely, since the MRT of the competitive economy without taxes and that of the socially planned economy are identical, the competitive path of consumption $\left\{c_{t}\right\}_{t=0}^{\infty}$ would be efficient if and only if the functional forms of the MRSs of these two economies are also identical:

$$
\frac{\hat{u}_{1}(t+1)+\beta \hat{u}_{2}(t+2)}{\hat{u}_{1}(t)+\beta \hat{u}_{2}(t+1)}=\frac{u_{1}(t+1)+\beta u_{2}(t+2)}{u_{1}(t)+\beta u_{2}(t+1)} .
$$

Therefore, the competitive equilibrium is efficient if and only if

$$
\hat{u}_{1}(t)+\beta \hat{u}_{2}(t+1)=\psi\left[u_{1}(t)+\beta u_{2}(t+1)\right],
$$

for all $t$ and for some constant $\psi$ along the competitive equilibrium path of consumption. Note that the efficiency condition (32) was obtained by abstracting from a specific functional form of the utility function. Therefore, the condition (32) can readily be used for alternative formulations of preferences, subject to habits and consumptions spillovers, in order to evaluate the welfare properties of the competitive equilibrium. It should be pointed 
out that the efficiency condition (32) also applies when capital income is not taxed and the tax rate on consumption is constant, $\tau_{t}^{c}=\tau_{t+1}^{c}$ for all $t$, as follows from the Euler condition (12).

As regards the additive specification of the utility function considered in this paper, recall that $u_{2}(t)=-\gamma u_{1}(t)$ and $\hat{u_{2}}(t)=-\hat{u_{1}}(t)(\gamma+\alpha) /(1-\theta)$. Hence, using these properties of the utility function (1) and the definition of $\phi_{t}$ the efficiency condition (32) becomes

$$
\frac{\hat{u}_{1}(t)}{u_{1}(t)}-\beta \phi_{t}\left(\frac{\gamma+\alpha}{1-\theta}\right)\left(\frac{\hat{u}_{1}(t+1)}{u_{1}(t+1)}\right)=\psi\left[1-\beta \gamma \phi_{t}\right] .
$$

Given that externalities enter into the utility function in an additive way, $u_{1}(t)$ and $\hat{u}_{1}(t)$ are linearly dependent for all $t$. In particular, according to (6) and (23), it holds that $\hat{u_{1}}(t)=(1-\theta) u_{1}(t)$ along the competitive equilibrium path of consumption. Therefore, the efficiency condition (33) simplifies to

$$
\beta[\alpha+\gamma(1-\psi)] \phi_{t}=1-\theta-\psi .
$$

Let us emphasize two important conclusions from the efficiency condition (34). First, since the growth rate $\phi_{t}$ of the marginal utility is not constant off the steady state of the competitive economy, the efficiency condition (34) does not hold along the transition to the steady state. Second, the externality associated with present average consumption does not generate inefficiency unless individuals' preferences are time-dependent. The following proposition states the result precisely:

Proposition 3. Let $\tau_{t}^{c}=\tau_{t+1}^{c}$ and $\tau_{t}^{k}=0$ for all $t$. Then:

(a) the competitive equilibrium is efficient at the steady state;

(b) the competitive equilibrium is efficient off the steady state if and only if at least one of the following sets of conditions holds: (i) $\alpha=\theta=0$ or (ii) $\gamma=\alpha=0$.

Proof: (a) Since the variable $\phi_{t}$ is constant at the steady state, the statement in part (a) follows directly from condition (34).

(b) First, when $\alpha=\theta=0$, there are no externalities and, hence, no source of inefficiency is present. Second, when $\gamma=\theta=\alpha=0$, the efficiency condition (33) simplifies to $\hat{u_{1}}(t)=\psi u_{1}(t)$, which is satisfied as follows from (6) and (23).

Under saddle-path stability, the statement in part (a) of the preceding proposition implies that the competitive equilibrium converges to an efficient stationary path. In fact, this property was already obtained in Section IV, where we saw that the stationary competitive solution with no taxes is identical to the stationary efficient solution. Part (b) of Proposition 3 tells us that inefficiency of the competitive equilibrium requires some consumption 
externality combined with time-dependent preferences. Since the externality arising from past average consumption generates this time dependency of preferences, the existence of only this externality is sufficient for inefficiency. However, the externality arising from current average consumption requires the presence of habits in order to make the equilibrium inefficient. Note that the situation with no habits $(\gamma=\alpha=0)$ has already been analyzed by Fisher and Hof (2000). In this case, efficiency just requires that the private and social marginal utilities be linearly proportional.

Assume first that there is no externality arising from past average consumption $(\alpha=0)$. If preferences are time-independent $(\gamma=0)$, the contemporaneous spillovers do not affect the unique margin of the individuals' decision problem, i.e., the intertemporal choice of consumption. Since own consumption and average consumption are perfect substitutes, the marginal utility corresponding to the socially planned economy is linearly proportional to that of the competitive economy, so that the MRS of both economies coincides. In contrast, if the contemporaneous externality coexists with a process of internal habit formation $(\theta \neq 0$ and $\gamma \neq 0)$, then the externality also affects the standard of the living of the next period and, thus, it distorts the intertemporal choice of consumption. In the presence of habits, current consumption has two countervailing effects on the individuals' objective: it increases current utility and simultaneously reduces future utility as a consequence of the increase in the future standard of living. Hence, since the marginal utility of present consumption in the socially planned economy differs from the corresponding one in the competitive economy, the overall effect of present consumption is also different in the two economies. The willingness of individuals to experience changes in consumption along the equilibrium path is then non-optimal. Therefore, the MRS of the competitive economy differs from that of the socially planned economy.

Assume now that there is no externality associated with present average consumption $(\theta=0)$. If spillovers arise from the lagged value of average consumption $(\alpha \neq 0)$, current consumption now affects the future standard of living in a way that individuals do not fully internalize. Therefore, the MRS of the competitive economy would also differ from that of the socially planned economy. Contrary to the previous case, the marginal utility of present consumption is now identical in both economies. However, the individuals' and the social planner's perceptions of the effect of present average consumption on future utility are now different.

\section{Optimal Taxation}

We have just shown that the competitive equilibrium can be inefficient along the transition to the steady state. Inefficiency arises from the discrepancy between the functional form of the before-tax MRS of the competitive 
economy and the corresponding one of the socially planned economy (see (12) and (25)). The government can thus design a tax policy that restores the efficiency of the competitive equilibrium by driving the after-tax competitive MRS to its efficient value. We will see next that the consumption tax and the capital income tax are alternative instruments that allow the decentralized economy to reach an efficient equilibrium path.

Evaluating the Euler condition (12) corresponding to the competitive economy along the efficient path, and dividing the resulting equation by the Euler condition (25) of the socially planned economy, we obtain the following optimal taxation condition:

$$
\frac{\operatorname{MRS}^{d}\left(\hat{c}_{t+2}, \hat{c}_{t+1}, \hat{c}_{t}, \hat{c}_{t-1}\right)}{\operatorname{MRS}^{p}\left(\hat{c}_{t+2}, \hat{c}_{t+1}, \hat{c}_{t}, \hat{c}_{t-1}\right)}=\left[\frac{1+\hat{\tau}_{t+1}^{c}}{1+\hat{\tau}_{t}^{c}}\right]\left[\frac{1+f^{\prime}\left(\hat{k}_{t+1}\right)-\delta}{1+\left(1-\hat{\tau}_{t+1}^{k}\right) f^{\prime}\left(\hat{k}_{t+1}\right)-\delta}\right],
$$

where $\hat{\tau}_{t}^{c}$ and $\hat{\tau}_{t}^{k}$ denote the optimal rates of the consumption tax and of the capital income tax in period $t$, respectively; $M R S^{d}\left(\hat{c_{t+2}}, \hat{c_{t+1}}, \hat{c_{t}}, \hat{c_{t-1}}\right)$ is the MRS corresponding to the competitive economy evaluated along the efficient consumption path (see (12)), and $M R S^{p}\left(\hat{c_{t+2}}, \hat{c_{t+1}}, \hat{c_{t}}, \hat{c_{t-1}}\right)$ is the MRS corresponding to the socially planned economy (see (25)). The next proposition characterizes the optimal tax rates:

\section{Proposition 4.}

(a) If $\operatorname{MRS}^{d}\left(\hat{c_{t+2}}, \hat{c_{t+1}}, \hat{c_{t}}, \hat{c_{t-1}}\right)>(<) \operatorname{MRS}^{p}\left(\hat{c_{t+2}}, \hat{c_{t+1}}, \hat{c_{t}}, \hat{c_{t-1}}\right)$ and $\hat{\tau}_{t+1}^{c}=\hat{\tau}_{t}^{c}$, then $\hat{\tau}_{t+1}^{k}>(<) 0$

(b) If $\operatorname{MRS}^{d}\left(\hat{c_{t+2}}, \hat{c_{t+1}}, \hat{c_{t}}, \hat{c_{t-1}}\right)>(<) \operatorname{MRS}^{p}\left(\hat{c_{t+2}}, \hat{c_{t+1}}, \hat{c_{t}}, \hat{c_{t-1}}\right)$ and $\hat{\tau}_{t+1}^{k}=0$, then $\hat{\tau}_{t+1}^{c}>(<) \hat{\tau}_{t}^{c}$.

(c) If $\operatorname{MRS}^{d}\left(\hat{c_{t+2}}, \hat{c_{t+1}}, \hat{c_{t}}, \hat{c_{t-1}}\right)=\operatorname{MRS} S^{d}\left(\hat{c_{t+2}}, \hat{c_{t+1}}, \hat{c_{t}}, \hat{c_{t-1}}\right)$, then to set $\hat{\tau}_{t+1}^{k}=0$ and $\hat{\tau}_{t+1}^{c}=\hat{\tau}_{t}^{c}$ constitutes an optimal tax policy.

Proof: The proposition follows directly from condition (35).

If the competitive MRS evaluated along the efficient path turns out to be larger than the efficient MRS evaluated along the same path, then the individuals' willingness to shift present consumption to the future would be too high. In this case, the decentralized economy can reach the efficient path through taxes that raise the price of future consumption in terms of present consumption in order to prevent consumption from being postponed. This can be achieved by means of either a positive tax rate on capital income or a sequence of tax rates on consumption increasing over time. Note that an increasing sequence of tax rates on consumption directly raises the after-tax relative price of future consumption. Moreover, a tax on capital income increases the cost of shifting resources to future periods and, thus, also raises the relative price of future consumption. Obviously, if the MRS of the 
competitive economy along an efficient path is smaller than that of the socially planned economy, then a welfare-maximizing government must either subsidize capital or impose a tax on consumption with a rate falling over time. ${ }^{6}$

In Section V we proved that the steady-state value of the MRS corresponding to the competitive economy without taxes (or with only a tax on consumption exhibiting a constant rate) coincides with that of the MRS of the socially planned economy. Therefore, Proposition 4 also establishes that a zero tax rate on capital income coupled with a constant tax rate on consumption constitutes an optimal policy at the steady state.

At this point, we can also characterize the dynamic behavior of the optimal tax rates as functions of the initial values of the state variables of the model. For this purpose, we first show from condition (35) that the evolution of both rates depends qualitatively on the transition of the efficient value of the growth rate $\hat{\phi}_{t}$ of the marginal utility. On the one hand, setting $\hat{\tau}_{t+1}^{c}=\hat{\tau}_{t}^{c}$ in (35), and from the definition of the variable $\hat{\phi}_{t}$, the optimal rate of the capital income tax becomes:

$$
\widehat{\tau}_{t+1}^{k}=\left[\frac{\beta(\alpha+\gamma \theta)\left(\hat{\phi}_{t+1}-\hat{\phi}_{t}\right)}{\left(1-\beta \gamma \hat{\phi}_{t+1}\right)\left(1-\theta-\beta(\gamma+\alpha) \hat{\phi}_{t}\right)}\right]\left[\frac{1+f^{\prime}\left(\hat{k}_{t+1}\right)-\delta}{f^{\prime}\left(\hat{k}_{t+1}\right)}\right] .
$$

On the other hand, imposing $\widehat{\tau}_{t+1}^{k}=0$ in (35), we obtain the following dynamic equation for the optimal rate of the consumption tax:

$$
\frac{\hat{\tau}_{t+1}^{c}-\hat{\tau}_{t}^{c}}{1+\hat{\tau}_{t}^{c}}=\frac{\beta(\alpha+\gamma \theta)\left(\hat{\phi}_{t+1}-\hat{\phi}_{t}\right)}{\left(1-\beta \gamma \hat{\phi}_{t}\right)\left(1-\theta-\beta(\gamma+\alpha) \hat{\phi}_{t+1}\right)} .
$$

The next proposition characterizes the optimal tax rates $\widehat{\tau}_{t+1}^{k}$ and $\hat{\tau}_{t+1}^{c}$ around the steady state:

\section{Proposition 5.}

(a) Assume $\alpha+\gamma \theta>(<) 0$ and $\hat{\tau}_{t+1}^{c}=\hat{\tau}_{t}^{c}$. If $\hat{\phi}_{t+1}>\hat{\phi}_{t}$ around the steady state, then $\hat{\tau}_{t+1}^{k}>(<) 0$. Conversely, if $\phi_{t+1}<\hat{\phi}_{t}$ around the steady state, then $\hat{\tau}_{t+1}^{k}<(>) 0$. If $\hat{\phi}_{t+1}=\hat{\phi}_{t}$, then $\hat{\tau}_{t+1}^{k}=0$.

(b) Assume that $\alpha+\gamma \theta>(<) 0$ and $\hat{\tau}_{t+1}^{k}=0$. If $\hat{\phi}_{t+1}>\hat{\phi}_{t}$ around the steady state, then $\hat{\tau}_{t+1}^{c}>(<) \hat{\tau}_{t}^{c}$. Conversely, if $\hat{\phi}_{t+1}<\hat{\phi}_{t}$ around the steady state, then $\hat{\tau}_{t+1}^{c}<(>) \hat{\tau}_{t}^{c}$. If $\hat{\phi}_{t+1}=\hat{\phi}_{t}$, then $\hat{\tau}_{t+1}^{c}=\hat{\tau}_{t}^{c}$.

\footnotetext{
${ }^{6}$ Note that our results on optimal taxation extend those of Fisher and Hof (2000), who disregard habit formation and consider externalities accruing only from contemporaneous average consumption.
} 
Proof: Parts (a) and (b) of the proposition follow directly from (36) and (37), respectively, since $\beta \gamma<1, \gamma+\alpha+\theta<1$ and $\hat{\phi}=1$ at a steady state.

Observe that the parameter $\alpha$ measures the distortion generated by the externality arising from past average consumption. Similarly, since the externality arising from current average consumption requires habits in order to generate inefficiency, $\gamma \theta$ measures the distortion which comes from the spillovers associated with current average consumption. Hence, $\alpha+\gamma \theta$ determines the sign of the net distortion generated by consumption spillovers. This explains the role of the sign of $\alpha+\gamma \theta$ in determining the dynamic behavior of optimal tax rates.

Let us also mention that, although the optimal tax rate on consumption characterized in Propositions 4 and 5 is time varying around the steady state, it converges to a constant value in order to allow for an efficient steady state in the long run. Similarly, the optimal tax rate on capital income should converge to zero.

Since our model contains two state variables, $\hat{k}_{t}$ and $\hat{c_{t-1}}$, the transition of $\hat{\phi}_{t}$ depends on the particular initial values of these two variables. Hence, this transition could be non-monotonic. This implies that the optimal tax rates could also exhibit non-monotonic behavior along the transition. ${ }^{7}$ More precisely, the optimal tax on capital income could be positive during some periods and become negative later on, or vice versa. Similarly, the optimal consumption tax could grow during a number of periods and decrease afterwards. We can illustrate this point by using the benchmark numerical example given in Section III. Let us assume that the initial values of the state values are $k_{0}=0.99 k$ and $c_{-1}=0.95 c$. For this economy, the optimal tax rate on capital income takes positive values, for $t \leqslant 7$, whereas it takes negative values for $t>7$. Similarly, the optimal tax rate on consumption is increasing for $t \leqslant 7$ and decreasing for $t>7$ for any arbitrarily given initial tax rate $\hat{\tau}_{0}^{c}$.

Let us make a final comment on an economic implication of the dynamic behavior of optimal taxes that we have just characterized. According to this model, two economies that start from the same initial capital stock will display different optimal tax rates if they do not share a common initial value $c_{-1}$ of the standard of living. This follows from the fact that not only the position of the capital stock with respect to its stationary value, but also the deviation of average past consumption of the economy with respect to its steady state, determines the amount of consumption competitively chosen by the individuals.

\footnotetext{
${ }^{7}$ Note that whether the MRS of the competitve equilibrium is larger or smaller than that of the socially planned economy depends on the sign of the externalities and on the relative position of the economies with respect to their steady state. Here, however, this relative position is driven by two state variables.
} 


\section{Conclusion}

In this paper we have analyzed the welfare properties of the competitive equilibrium of an economy with capital accumulation, where we have assumed that preferences vary over time due to the existence of a process of habit formation and of consumption spillovers. Individuals will not derive utility from their absolute level of consumption at a given period, but from the difference between consumption and a reference level. This reference consumption is determined by an additive combination of past own consumption, the lagged value of average consumption and current average consumption.

This departure from the more traditional formulations of preferences has consequences for the dynamic behavior of both consumption and capital. In particular, consumption externalities could be an obvious source of inefficiency. More precisely, under the additive specification of preferences that we have assumed in this paper, these externalities affect the welfare properties of the competitive equilibrium only if preferences are time-dependent. Hence, contemporaneous consumption spillovers do not generate any kind of suboptimality as long as individuals' utility is not subject to either a process of habit formation or consumption spillovers from the lagged value of average consumption. This occurs because, in this case, the functional form of the marginal rate of substitution between consumption in different periods is identical to the efficient marginal rate of substitution. Consumption spillovers only break down the previous equality between the two marginal rates of substitution through their effect on the future standard of living. Obviously, this discrepancy calls for some public intervention aimed at restoring efficiency. If consumption spillovers affect habits in such a way that individuals' willingness to shift consumption to the future along an efficient path is below (above) the efficient one, the government maximizes welfare by means of either subsidizing (taxing) capital or taxing consumption with tax rates falling (increasing) over time. Furthermore, the optimal rates of the capital income tax and of the consumption tax converge to zero and to a constant value, respectively.

\section{Appendix}

\section{Proof of Proposition 1}

We obtain the stationary values (19)-(21) by letting $k_{t}=k, c_{t-1}=c, x_{t}=x$ and $\phi_{t}=\phi$ for all $t$ in the system of difference equations (13), (15), (16) and (17) Since $f^{\prime}(k)>0$ and $\beta\left(1-\tau^{k}\right)>0$, equation (20) implies that condition (18) should hold. Moreover, concavity implies that $f(k) / k>f^{\prime}(k)$, whereas (20) implies that $f^{\prime}(k)>n+\delta$ whenever $\beta\left(1-\tau^{k}\right) \in(0,1)$. Thus, we get that $f(k) / k>n+\delta$ which, together with $(21)$, implies that $c>0$. 
Next we show that the previous steady state is indeed a well-defined stationary equilibrium of the economy. Note first that the argument in the instantaneous utility (1) is always strictly positive at the steady state since $x=1$ and $\gamma+\alpha+\theta<1$. Therefore, the objective function of each individual is well-defined around a competitive steady state.

Using (6) the transversality condition (11) becomes

$$
\lim _{t \rightarrow \infty} \beta^{t} u(t)\left(\frac{x_{t}}{(1-\theta) x_{t}-(\gamma+\alpha)}\right)=0 .
$$

Since both $x_{t}$ and $u(t)$ are constant at the steady state, the previous condition holds because $\beta$ belongs to the open interval $(0,1) x=1$ and $\gamma+\alpha+\theta<1$.

According to (7) and (14), the first-order condition (8) at the steady state becomes

$$
\lambda_{t}=\frac{\beta^{t} u_{1}(t)-\beta^{t+1} \gamma u_{1}(t+1)}{1+\tau^{c}}=\beta^{t} u_{1}(t)\left(\frac{1-\beta \gamma \phi}{1+\tau^{c}}\right)
$$

Since $\phi=1, u_{1}(t)>0$ and $\tau^{\mathrm{c}}>-1$, we observe that $\lambda_{\mathrm{t}}>0$ if and only if $\beta \gamma<1$. The last inequality always holds since both $\beta$ and $\gamma$ belong to the open interval $(0,1)$. Finally, using the fact that $u_{\mathrm{t}}(\mathrm{t})$ is constant at a steady state and substituting $\left(\mathrm{A}_{1}\right)$ into the transversality condition (10), we can conclude that this transversality condition is also satisfied at the steady state.

\section{References}

Abel, A. (1990), Asset Prices under Habit Formation and Catching Up with the Joneses, American Economic Review 80, 38-42.

Abel, A. (1999), Risk Premia and Term Premia in General Equilibrium, Journal of Monetary Economics 43, 3-33.

Alonso-Carrera, J., Caballé, J. and Raurich, X. (2004), Growth, Habit Formation, and Catching Up with the Joneses, forthcoming in European Economic Review.

Brock, W. and Turnovsky, S. (1981), The Analysis of Macroeconomic Policies in Perfect Foresight Equilibrium, International Economic Review 22, 179-209.

Campbell, J. Y. and Cochrane J. H. (1999), By Force of Habit: A Consumption-Based Explanation of Aggregate Stock Market Behavior, Journal of Political Economy 107, 205-251.

Carrasco, R., Labeaga, J. M. and López, J. D. (2002), Consumption and Habits: Evidence from Panel Data, CEPR Discussion Paper no. 3520.

Carroll, C. (2000), Solving Consumption Models with Multiplicative Habits, Economics Letters 68, 67-77.

Carroll, C., Overland, J. and Weil, D. (1997), Comparison Utility in a Growth Model, Journal of Economic Growth 2, 339-367.

Carroll, C., Overland, J. and Weil, D. (2000), Saving and Growth with Habit Formation, American Economic Review 90, 341-355.

Constantinides, G. M. (1990), Habit Formation: A Resolution of the Equity Premium Puzzle, Journal of Political Economy 98, 519-543.

Cooley, T. F. and Prescott, E. C. (1995), Economic Growth and Business Cycles, in T. F. Cooley (ed.), Frontiers of Business Cycle Research, Princeton University Press, Princeton, NJ. 
Dynan, K. E. (2000), Habit Formation in Consumer Preferences: Evidence from Panel Data, American Economic Review 90, 391-406.

Ferson, W. E. and Constantinides, G. M. (1991), Habit Persistence and Durability in Aggregate Consumption: Empirical Test, Journal of Financial Economics 29, 199-240.

Fisher, W. H. and Hof, F. X. (2000), Relative Consumption, Economic Growth, and Taxation, Journal of Economics 72, 241-262.

Galí, J. (1994), Keeping Up with the Joneses: Consumption Externalities, Portfolio Choice, and Asset Prices, Journal of Money, Credit and Banking 26, 1-8.

Hall, R. (1971), The Dynamic Effects of Fiscal Policy in an Economy with Foresight, Review of Economic Studies 38, 229-244.

Heaton, J. (1995), An Empirical Investigation of Asset Pricing with Temporally Dependent Preference Specifications, Econometrica 63, 681-717.

Lettau, M. and Uhlig, H. (2000), Can Habit Formation Be Reconciled with Business Cycles Facts?, Review of Economic Dynamics 3, 79-99.

Ljungqvist, L. and Uhlig, H. (2000), Tax Policy and Aggregate Demand Management Under Catching Up with the Joneses, American Economic Review 90, 356-366.

Shieh, J., Lai, C. and Chang, W. (2000), Addictive Behaviour and Endogenous Growth, Journal of Economics 72, 263-273.

Solnick, S. J. and Hemenway, D. (1998), Is More Always Better? A Survey on Positional Concerns, Journal of Economic Behavior and Organization 37, 373-383.

First version submitted September 2002;

final version received June 2003. 
